\title{
Fintech, Regtech and Suptech: Three Dimensional Approaches to Digital Finance
}

\author{
G.V. Satya Sekhar ${ }^{1}$
}

\begin{abstract}
Every institution is now doing business transactions through digital financing system. Digital financing solutions offer great potential to overcome challenges and contribute toward achieving universal access to financial services. However, it is noticed that insufficiency of technological up-gradation and various issues created by hackers that might include fraudulent online transactions as an example, hampers people who are not aware of the other side of technology.

There are three stages in the implementation of digital finance viz., Fintech, Regtech and Suptech. 'Fintech' is an application of Technology for financial services that include; digital payments and e-money, international remittances, personal and business loans, peer-topeer lending platforms, crowd funding platforms, Robo-advisors, Crypto currencies like Bitcoin, Altcoin, etc. 'Regtech' is a contraction of the terms 'regulatory' and 'technology' and it describes the context of regulatory monitoring, reporting, and compliance. 'Suptech' is derived from 'Supervision' and 'Technology', which monitors 'Fintech' and 'Regtech'. The rise of Fintech will undermine the widespread assumption that the primary source of systemic risk in the financial sector is the domination of large, "systemically important" banks and other financial institutions. On this backdrop, this paper aimed to explore the importance of Fintech, Regtech, and Suptech as three stage approach to digital finance.
\end{abstract}

This paper makes a focus as the special dynamics regarding how Fintech, Regtech, and Suptech as three stage approach to digital finance work and will become the better substitute of banks and other financial systems. Based on review of secondary sources, this paper highlights: 1. the problems and obstacles faced by corporate entities in digital finance and 2 . the interdependency of three dimensions of technology viz., Fintech, Regtech and Suptech.

Keywords: Digital finance, Financial literacy, Fintech, Regtech and Suptech.

1 G.V.Satya Sekhar is the Associate Professor for GITAM Deemed to be University, Visakhapatnam-India. 


\section{Introduction}

\subsection{Background}

Every institution is now doing business transactions through digital financing system. Digital technological solutions offer great potential to overcome challenges and contribute toward achieving universal access to financial services. But, it is noticed that various issues created by hackers, fraudulent online transactions, insufficiency of technological up-gradation hampers people who are not aware of the other side of technology.

There are three stages in implementation of digital finance viz., Fintech, Regtech and Suptech Whereas, 'Fintech' is an application of Technology for financial services, for instance: digita payments and e-money, international remittances, personal and business loans, peer-to-peer lending platforms, crowd funding platforms, Robo-advisors, Crypto currencies like Bitcoin, Altcoin, etc. The word 'Regtech' is a contraction of the terms 'regulatory' and 'technology' and describes the context of regulatory monitoring, reporting, and compliance. The word 'Suptech' is derived from 'Supervision' and 'Technology', which regulates 'Fintech' and 'Regtech'. The rise of Fintechwill undermine the widespread assumption that the primary source of systemic risk in the financial sector is the domination of large, "systemically important" banks and other financial institutions.

\subsection{Problems concerning the technologies of financial transactions:}

To implement digital finance in corporate entities, it should have technical know-how of three aspects viz., Fintech, Regtech and Suptech. These three are interdependent and cannot be isolated. There are various threats like Hacking, manipulation, Hardware failure, Software failure; lapses in programming, lack of customization in software etc. are some of major problems in implementation of digital finance. A small lapse in software costs very huge loss to corporate entity.

\subsection{Objectives}

\subsubsection{General objective}

To understand the problems concerning in the digitalization of financial transactions.

\subsubsection{Specific objectives:}

To understand the interrelation between Fintech, Regtech, and Sup-tech.

To make appraise of a three dimensional approach to digital finance and the role of Fintech, Regtech and Suptech in digital finance.

\section{Review of Literature}

The growing need of financial innovation and use of technology in stimulating economic growth and businesses operations indeed can be viewed by explaining functions it has performed (Miller \& Merton, 1992).It is necessary to take a close look at the main features of the current wave of financial innovation and evaluate objectively. It is also essential to identify the lessons that are learned from the economic change and innovation (Verghese, 1990).The factors primarily responsible for technological advancement are: innovation in financial instruments, financial processes, financial strategies based on the tax advantages, reduction of risk of volatility in interest rates, reallocation of risk, increase in liquidity, etc (Finnerty, 2002).

What financial product and process changes have occurred over the last twenty to twenty-five years in international financial markets? What is the assessment of the recent developments surrounding financial innovation, including their financial stability and national policymaking impact? These questions are addressed in a study conducted by Richard Levich et al., (1988).The innovated financial technology has created various business models as well as new customer needs. They affect different aspects of the economics, including the payment services, the banking industry, and the financial regulations (Salmony, 2014). The internet was able to connect and be widely used in most countries around the world, and so it became an invaluable support tool for the ongoing development of Fintech (Desai, 2015).

The Indian exchanges of the digital money are gearing up to launch Bitcoin futures; but first, they want to integrate other crypto-currencies such as Ethereum, Ripple, and Bitcoin Cash (BCH) on their platform (Kurup, 2017). Other than bitcoins, there are about 1,000 alternative coins (Altcoins) in the global market, with Ethereum being the most popular. Altcoins are crypto-currencies that were launched after the success of Bitcoin. In India, Bitcoins have been available since 2012, and now have 8-9 trading platforms and over a million users".

Fintech poses a set of unique challenges to financial regulation, challenges that require us to question many of our fundamental understandings about the creation and propagation of systemic risk in the economy. In particular, the rise of Fintech will undermine the widespread assumption that the primary source of systemic risk in the financial sector is the domination of large, "systemically important" banks and other financial institutions (William, 2018)." It was found that regulations tend to spur a series of financial innovations. There exists a positive relationship between education and income and use of the new financial Technology by consumers. Financial innovators tend to gain by first mover advantages and re compensated well for their efforts (Frame et al.,2004).

Vasanth and Stein (2017) mentioned that "we examine the potential trajectories and impacts of Fintech innovation on incumbent and new business models in the finance industry. We provide a framework for understanding the value created through various types of platforms in financial services. This framework provides a natural mechanism for thinking about Fintech winners and losers and for predicting the trajectory of changes in the industry. It 
also provides a description of the possible strategies that innovators, incumbents, and the currently dominant Internet players can pursue."

Arner et al., (2015) examined the evolution of Fintech using a broad definition of the term that proposed that all incumbent and new financial companies and industry participants could be regarded as Fintech, regardless of their size, business model or product portfolio.

Legislators are currently struggling to fit Fintech into existing legal frameworks, as these were designed for a different environment consisting of large, traditional financial institutions. Too much regulation can burden innovation efforts, while under-regulation can impose an unfair advantage on new entrants due to their lower legal costs and overheads, and create higher social costs due to fraudulent activity and non-existent customer protection (Douglas, 2016)

The 2008 global financial crisis represented a pivotal moment that separated prior phases of the development of financial Technology (Fintech) and regulatory Technology (Regtech) from the current paradigm (Douglas et al., 2017). In addition to this, the recent pandemic situation and phase-wise lockdown during 2020-2021, also necessitated the Regtech mechanism to monitor Fintech and Suptech systems. The following diagram shows interrelation between these stages.

RegTech to date has focused on the digitization of manual reporting and compliance processes, for example in the context of know-your-customer requirements. This offers tremendous cost savings to the financial services industry and regulators. However, the potential of RegTech is far greater - it could enable a close to real-time and proportionate regulatory regime that identifies and addresses risk while also facilitating more efficien regulatory compliance (Arner et al., 2016).

\begin{tabular}{|c|c|}
\hline Figure-1: Three Stage Approach t & ital Finance \\
\hline $\begin{array}{l}\text { DIGITAL FINANCE } \\
\text { IMPLEMENTATION }\end{array}$ & \\
\hline$\uparrow$ & \\
\hline SUP & \\
\hline & $\uparrow$ \\
\hline & REG TECH \\
\hline & FINTECH \\
\hline
\end{tabular}

\section{Methodology}

This review paper is addressed various issues like: i) organized literature, ii) evaluate relevant literature, iii) identified patterns and trends in the literature, iv) synthesized literature and v finally research gaps and recommend new research areas.

The studies reveal that the smartcards are slowly replaced by mobile wallets even though there are hackers and fraudulent call centre operators are cheating people. At the same time, crowd funding is becoming popular tool for venture finance.

This paper made focus of literature on genesis of financial innovation, digital currency, fintech, regtech and suptech. The following insights are found:

i. There is a dire need for financial innovation and secured financial products for implementation of digital finance in corporate sector (Finnerty, 2002).

ii. There are many doubts about legal sanctity for Bitcoins for business operation in India ( Kurup, 2017).

iii. The lapses in implementation of fintech, Regtech and Suptech lead to huge amount of loss to corporate entities (Vasanth, \& Stein 2017).

iv. Financial innovators tend to gain by first mover advantages and re compensated well for their efforts (Frame et al., 2004)

v. Too much regulation can burden innovation efforts, while under-regulation can impose an unfair advantage on new entrants due to their lower legal costs and overheads, and create higher social costs due to fraudulent activity and non-existent customer protection (Douglas, 2016)

vi. RegTech solutions can be designed to paint a 360-degree view of compliance and risk in real-time, while single-rule solutions are aimed at one specific area. ${ }^{2}$

\section{Results and Discussions}

\subsection{Structure and functions of fintech}

The origin of Fintech is said to be the year 1918, during this time, 'The Telegraph Inc.' played a very important role in transfer of money from bank to bank using Fedwire Funds Service. Credit card was invented in 1950. The first electronic stock market was established in 1970. Net banking evolved during 1990s. At present, smart phones and mobile applications are developed. Now, we can transfer money for financial transactions through smart phones. 


\subsection{The framework of fintech: Figure 2 depicts the framework of Fintech}

\subsubsection{Smart Cards}

The recent developments in software applications viz., UPI, Paytm, Phone-pe etc., offers the greatest scope for competition with the traditional sector, as these tech companies can leverage off their pre-existing large customer bases to roll out new financial products and services. These mobile apps are reducing demand for SMART cards.

\subsubsection{Mobile Wallets}

A mobile wallet application like GooglePay, AndroidPay, ApplePay, Alipay, PayPal are used for electronic payments. One has to download the particular mobile wallet app on their phone and add information of their debit/credit card details which will be stored securely. However, hacking through fraudulent calls are obstacles to this type of payment.

\subsubsection{ONLINE/Net banking}

Electronic Clearing System (ECS): ECS is an electronics mode of payment/receipt for transactions that are repetitive and periodic in nature. ECS is used by institutions for making bulk payment or bulk collection of amounts. Essentially, ECS facilitates bulk transfer of monies from one bank account to many bank accounts or vice versa.

- Real Time Gross Settlement (RTGS): This enables money to move from one bank to another on a real time and gross basis. 'Real time' means the beneficiary bank receives the instructions for fund transfer immediately and gross means that it is not bunched with any other transaction and funds transfer instructions happen individually. RTGS is the fastest mode of fund transfer, which is secure and irrevocable. This adds to the present fund transfer channels available to the customers.

- National Electronic Funds Transfer (NEFT): This is a nation-wide payment system facilitating one-to-one funds transfer. Under this Scheme, account holders can electronically transfer funds from any bank branch to any individual, firm or corporate having an account with any other bank branch across globe. Like RTGS, NEFT also transfers funds from one bank, but unlike RTGS the settlement takes place in batches.

- Cheque Truncation System (CTS): The process of sending the cheque in electronic image form by the collecting bank to the paying bank, transmitted to the drawee branch for payment through the clearing house is called CTS. This system eliminates the cumbersome physical presentation of the cheque to the paying bank.

\subsection{Digital currencies (D.C.s)}

Digital currencies (D.C.s) are issued by private developers and denominated in their own unit of account. They are obtained, stored, accessed, and transacted electronically and neither denominated in any sovereign currency nor issued or backed by any government or central bank. D.C. schemes comprise two key elements: (i) digital representation of value or 'currency' that can be transferred between parties; and (ii) the way in which value is transferred from a payer to a payee. Bitcoin is a popular example of Digital Currency. It helps to facilitate peer-to-peer exchange at low transactional costs and faster transaction time. D.C. schemes are also known as 'crypto currencies' as it uses cryptographic techniques. Crypto currencies derive their value from the expectation that others will be willing to exchange it for sovereign currency or goods and services. The inferences of D.C.s for financial firms, markets and system will depend on the extent of its acceptability among users.

\subsection{Crowd funding}

Crowd funding is a way of raising debt and equity with a collective effort of multiple investors through an internet based platform. A small amount of money is pooled from numerous investors to invest in a new venture. It is a platform that matches borrowers or issuers with savers or investors. This Platform providers offer a range of information about the potential borrowers/issuers, ranging from credit ratings to business model to verification of information. Crowd funding is also known as Peer-to-Peer Lending (P2P), wherein money is lent to individuals or businesses through online services.

\subsection{An overview of regtech}

Figure 3 is given to make aware of the structure of Regtech.

Regtech is used to regulate and monitor transactions relating to digital finance. Banking and financial institutions today have a lot to gain from Regtech. Keeping in mind the growing list of regulatory obligations financial organizations have to comply with, and the consequences of noncompliance and the large fines associated with this.

RegTech's ability to deliver tools to reach compliance more quickly, and at a lower cost, is a huge benefit for organizations and will give early adopters a competitive advantage. Early adopters and organizations who implement Regtech into their governance, risk and compliance strategies will be the beneficiaries. For many processes, especially those that heavily involve client data like Know Your Customer (KYC) requirements, the end customer also receives an enhanced experience by having a more streamlined process in place. Organizations that use Technology to safeguard against breaches and protect client data will also benefit the client. The following are various applications used in Regtech.

\subsubsection{Smart contracts}

A smart contract is a computer protocol that can self-execute, self-enforce, self-verify, and self-constrain the performance of a contract. It allows the performance of credible transactions without third parties. The widespread adoption of smart contracts in financial services could be facilitated by the establishment of distributed ledger technology. Smart contracts allow to perform credible transactions without third parties. These transactions are trackable and irreversible. 


\subsubsection{Cloud based service}

Cloud-based services can deliver internet-based access to a shared pool of computing resources that can be quickly and easily deployed. The use of these services is an importan enabler for new entrants to the financial services arena to set up quickly and with low start-up cost, with easy options to expand their capability as the firm grows. Depending on the type of services of the cloud service availed; it can potentially pose several challenges including the ability of jurisdictional enforcement authorities to effectively ensure security of data.

\subsubsection{Robo advice}

It is the provision of financial advice by automated, money management providers, thereby disintermediation of human financial advisors and reducing costs. It can offer more investor choice, especially for low and middle income investors who do not have access to the wealth management divisions of the banks. They use client information and algorithms to develop automated portfolio allocation and investment recommendations that are meant to be tailored to the individual client.

\subsubsection{Data analytics}

Companies looking to achieve a competitive edge through 'Artificial Intelligence' (AI) need to work through the implications of machines that can learn, conduct human interactions, and engage in other high-level functions at an unmatched scale and speed. They need to identify what machines do better than humans and vice versa, develop complementary roles and responsibilities for each, and redesign processes accordingly. AI often requires, for example, a new structure, of both centralized and decentralized activities, that can be challenging to implement.

\subsubsection{Classification of suptech applications}

Figure 3 shows interdependency of Fintech and Regtech and its monitoring technology viz., Suptech. The Technology used for supervision and decision making is called 'Suptech'. The following are various applications relating to Suptech.

\subsubsection{Applications of artificial intelligence (A.I.)}

$\mathrm{AI}$ is a branch of computer science that deals with the concept of intelligent machines. It is based on the principles of how humans think and reason and making the machine emulate the same. The way humans' reason based on the knowledge and past experiences, AI too reasons based on data and learning algorithms (Poole and Mackworth, 2017). Machine learning and Robotics are the major fields in the area of Artificial Intelligence. Artificial intelligence provides customized experience, efficiency, improvement in productivity and all together cost reduction. Recent emerging applications in finance sector are blockchain, chatboats, personalised financial advice and fraud detection mechanism. As a result of the government's initiatives, there has been a sharp increase in consumer adoption of Fintech.

\subsubsection{Fraud detection}

People are creatures of habit, and a slight change in their routine could signal a problem. Accessing internet banking from a different browser or transferring larger amounts than normal are signs of a possible fraud. The A.I. should be able to detect if this is a real threat or a one of a kind situation by correlating other readily available information about the client.

\subsubsection{Chatboats}

Chatboats are also implemented by financial institutions to help customers navigate through products and feel they matter. For simple operations, most people wouldn't be able to tell if they are talking to a real person following a script or a boat driven by A.I. From simple customer service interactions to analyzing legal contracts, A.I. chatboats are rapidly becoming more and more prevalent in our day-to-day lives.

\subsubsection{Physical and digital merger}

Fintech has made it possible for banks to reach customers who are data rich but credit poor. In country like India, where so many people still don't have access to banking facilities, Fintech works better by offering a 'phygital' (a combination of physical and digital) experience. The objective here is effective self-service that enables customers to walk into a branch and make use of basic automated services. Canara Bank has successfully implemented such a system with CANDI, and more banks will follow suit in 2018 to remove the boundaries between physical and digital banking (yourstory.com).

\subsubsection{Cognitive analytics}

Cognitive solutions may be deployed from the cloud and offered as a hosted service or may be deployed on in-house servers depending on the organisational requirements. In digital banking, there are several new applications of cognitive analytics and A.I. that are aimed at improving customer experience, increasing engagement, gaining a deeper understanding of customer behavior and making the customer interactions with the bank frictionless. In many instances, AI-powered bots are already beginning to perform functions that require complex thinking and contextual understanding.

\subsubsection{Augmented reality (A.R.)}

A.R. is the integration of virtual and real world. Unlike Virtual reality (V.R.), which creates artificial environment, A.R. uses the existing environment thus creating a unique experience. A.R. can be displayed by using smart devices such as smart phones or tablets. However, with ongoing research on inclusion of A.R. functionality in other devices, future may see a wide variety of ways to experience A.R. Innovative apps such as Layar, an iPhone app provides local information whereas products like Tissot watches and Olympus Cameras have webpages that enable to experience virtual products. Lego has point of sale display that lets kids to play with the toy inside the box which they are holding. 


\subsubsection{Internet of things (IoT)}

It is a concept of connecting devices that are embedded with some sort of electronics to communicate with other devices as well as exchange data. It helps in extending the internet services from standard devices such as computer, laptops and smart phones to everyday objects like home appliances or vehicles. One can monitor or even control the devices remotely using internet. IoT provides the basis for smart home solutions of automated devices with no or less human intervention.

\subsubsection{Big data tools}

Enormous amounts of data are generated at every moment from different sources. It could be structured, semi structured and unstructured. Social media has given rise to lots of data that carries perceptions and useful insights that can be used by an organization for gaining competitive edge. Technologies like NoSQL databases and the MapReduce model are widely used in big data that helps in working with large amount of data. Big companies use this Technology to store and analyze huge data and use it for precise user targeting, machine learning, optical recognition and more.

\subsubsection{Blockchain}

Blockchain is a list of records called as blocks which are linked with cryptography. It is used by crypto currencies. Blockchain provides a network that enables various stakeholders to transact with trust, security and anonymity. Blockchain is essentially a distributed database that contains a chronological order of all transactions or digital events that happened among the participatory parties. All transactions in the network are represented in terms of block and broadcasted to participants in the network, verified, time stamped and linked with the prior blocks in the network to form a sequence of blocks known as Blockchain.

\subsection{Forensic tols-A success factor for suptech}

Forensic tools could also be used to navigate information systems for evidence of malfeasance such as information deletion, violations in policies and unauthorized access. These tools can help the company legal counsels to prepare for a lawsuit to be filed against the fraudster. Apart from the internal controls, banks need to also educate the customers. Since the methods used by cyber-criminals to target the sensitive financial data are sophisticated and constantly changing, banks must look at existing security controls with a new approach and risk appetite. Figure 4 depicts the framework of Suptech.

- Automated Analysis Tools: Today, the industry is increasingly aware of the need for automated analysis tools that could easily identify and report fraud attempts in a timely manner. Solution providers are now providing real-time transaction screening, thirdparty screening as well as consent solutions.

- Data Visualization Tools: These are being used to provide a visual representation of complex data and transaction patterns and outliers to translate multidimensional

data into meaningful pictures or graphics which could help the banks to easily track troublesome digital footprints.

- Behavioral Analytics: This is helping the banks identify fraudsters disguised as customers. The data analytics implemented by the banks to understand customer behavior, preferences, etc are also helping in the detection of fraudulent activity either in real-time.

- Deep Learning: Internet payment companies providing alternatives to traditional money transfer methods are using deep machine learning, a new approach to machine learning and artificial intelligence that is great at identifying complex patterns and characteristics of cybercrime and online fraud.

\subsection{Summary}

This paper deals with three dimensional approaches viz., Fintech, Regtech and Suptech. Everyone needs to understand technological concepts and tools involved in digital financial world. As Fintech helps corporate entities to connect with customers via Technology, Regtech helps them meet regulatory requirements via Technology. Regtech utilizes various technologies such as machine learning and artificial intelligence to establish enterprisewide data governance and reporting. These new technologies replace the current manual processes for modeling and reporting. With the ever-changing regulatory landscape, Regtech enhances the ability for institutions to remain compliant with critical regulations such as the Bank Secrecy Act (BSA), including know-your-customer (KYC) and suspicious activity reporting. Regtech also simplifies the data-reporting requirements under a number of regulations including such as Basel-3, CCAR, and MIFID II to name a few. Hence, it can be concluded that 'Fintech'. 'Regtech' and 'Suptech' should go hand-in-hand.

\subsection{Discussion and conclusion}

1. This paper finds that there is interdependency of three dimensions of digital finance viz., Fntech, Regtech and Suptech.

2. There is a dire need to examine various characteristics like integrity, honesty and loyalty of employees along with technological implementation in corporate entity.

3. Now-a-days we believe in machine (computer and software) rather than man to supervise. If there are lapses in 'Suptech' then the other two aspects viz., Regtech and Fintech will definitely fail.

4. Too much dependence on 'Artificial Intelligence' is also dangerous. The Bank of England's former chief economist, Andy Haldane makes comparison of human and artificial intelligence decision-making capabilities. ${ }^{3}$

5. Researchers should think better ways to control frauds, hackers and manipulators to prevent loss to corporate entities.

6. Corporate entities should make a suitable plan of action and design alternative to detect frauds.

3. https://www.centralbanking.com/fintech/regtech-suptech/7869496/haldane-warns-against-blind-trust-in-ai NJMSR Volume IV Issue I 


\section{References}

Arner, Douglas W. and Arner, Douglas W. and Barberis, Janos Nathan and Buckley, Ross P (2016). The Emergence of Regtech 2.0: From Know Your Customer to Know Your Dat. Journal of Financial Transformation, Available at http://dx.doi.org/10.2139/ssrn.3044280.

Arner, D. W., Barberis, J. N., \& Buckley, R. P(2015). The Evolution of Fintech: A New Post-Crisis Paradigm? Available at SSRN 2676553.

David LEE KuoChuen(2016). Emergence of Fintech and the LASIC Principles. Electronic copy available at: $\mathrm{http}: / /$ ssrn.com/abstract $=2668049$

Desai, F.(2015). The Evolution of Fintech. Forbes. Available: http://www.forbes.com/sites/ falgunidesai/2015/12/13/the-evolution-of-Fintech/\#349c7f184ccb.

Douglas W. Arner, JànosBarberis, and Ross P. Buckley (2016).Fintech, Regtech and the Reconceptualization of Financial Regulation. Source: http://ssrn.com/abstract=2847806.

DouglasW. ArnerJanos Barberiseds.RossP.Buckley (2017).Fintech and Regtech in a Nutshell, and the Future in a Sandbox , Research Foundation Briefs,3(4).

Douglas, J. L. (2016). New Wine Into Old Bottles: Fintech Meets the Bank Regulatory World. North Carolina Banking Institute, 20 (1), p. 17.

Dushnitsky, G., Guerini, M., Piva, E. and Rossi-Lamastra, C(2016). Crowd Funding in Europe: Determinants of platform Creation Across Countries. California Management Review, 58, 44-71.

Gilbert. C., Bower, J.(2002). Disruptive Change: When trying harder is part of the Problem. Harvard Business Review May, 94-101.

Gonzalez, A. G. (2004). PayPal: The Legal Status of C2C Payment Systems. Computer Law \& Security Review, 20(7), 293-299.

IoannisAnagnostopoulos (2018).Fintech and Regtech: Impact on Regulators and Banks. Journal of Economics and Business. https://doi.org/10.1016/j.jeconbus.2018.07.003

McGrath, R. G (2010). Business models: A discovery driven approach. Long Range Planning, 43, 247-261.

Magretta, J (2002). Why business models matter. Harvard Business Review, 80, 86-92.

Megha Jain and Prof. (Dr.) G.S. Popli (2015).Role of Information Technology in the development of Banking Sector in India. Source: http://ssrn.com/abstract=2151162.

Sanmugam, A (2012).Factors determining consumer adoption of Internet Banking. Electronic copy available at: http://ssrn.com/abstract=1021484.

Santiago Fernandez De Lis, et al (2016). Regtech-The new Magic Word. Fintech, March.

Salmony, M (2014). Access to accounts: Why Banks Should Embrace an Open Future. Journal of Payments Strategy \&Systems, 8 (2), 169-170.

'Fintech, Regtech and Suptech: What they Mean for Financial Supervision', Toronto Centre, TC Notes-practical leadership and technical guidance from Toronto centre, Aug, 2017.

Institute of International Finance, Regtech: Exploring Solutions for Regulatory Challenges, 02 Oct 2015.

Vasant Dhar and Roger M. Stein (2017). Fintech Platforms and Strategy. MIT Sloan School Working Paper 5183-16.
William Magnuson (2018).Regulating Fintech.Vanderbilt Law Review, 71(4).

ZHOU Weihuan, Douglas W. Arner., Ross P. Buckley (2015). Regulation of Digital Financial Services

In China: Last Mover Advantage?. Tsinghua China Law Review, 8(25), 26-62.
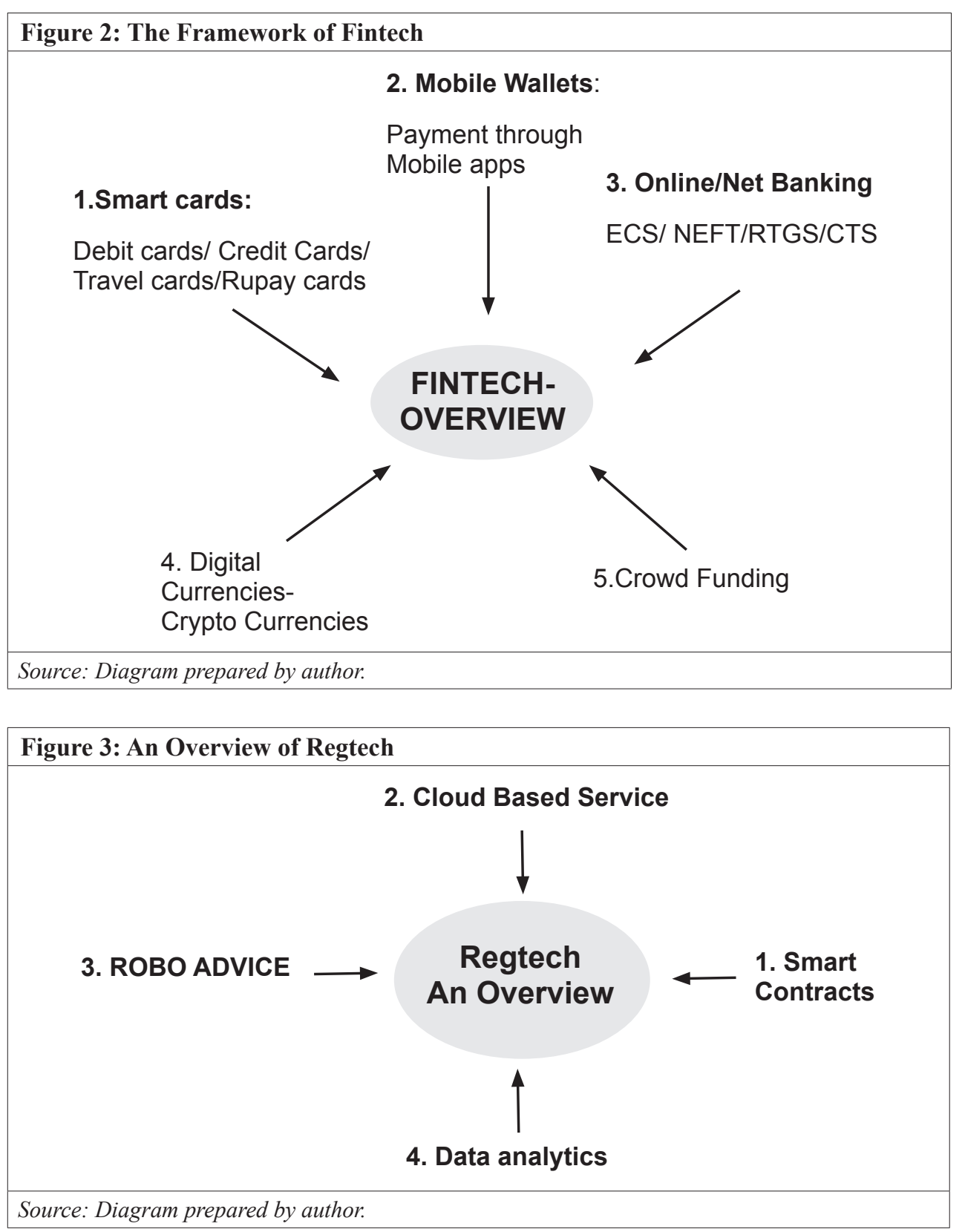
Figure 4: Suptech Diagram

\section{Fraud Detection}

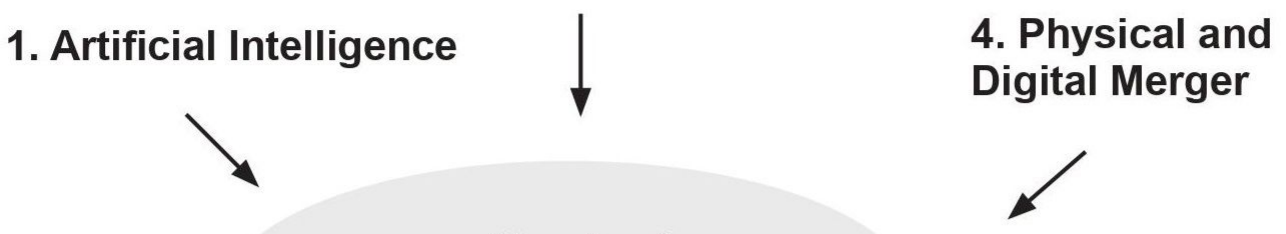

Suptech -Supervisory technology 5. Cognitive analysis

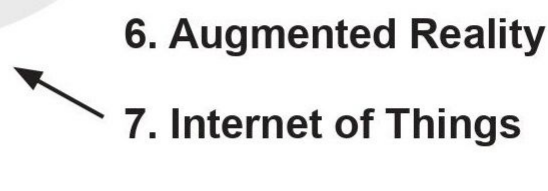

3. Chat boats
8. Big Data Tools
9. Block Chain

Source: Diagram prepared by author. 